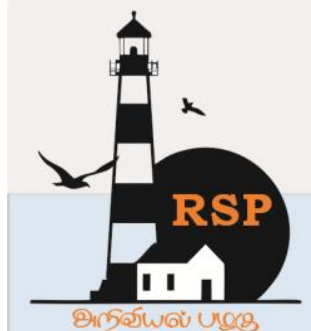

\title{
A Case Study on Cyber bullying
}

Shubhangi Tanejal,Ruchi Pal ${ }^{2}$, Shiwangi Vishwakarma ${ }^{3}$, Rakesh Kumar ${ }^{4}$

${ }^{1}$ Master of Mathematics, Maharishi Dayanand University, Rohtak, Haryana

${ }^{2}$ Master of Education, Sharda University, Greater noida

${ }^{3}$ Master of arts (Political Science), IGNOU

${ }^{4}$ Professor, Department of Education, Gautam College Of Education, Chhapra, Bihar

\section{Abstract}

Cyber bullying is a threat to the persons who are very socially active in various social media platforms. $S$ in this paper we deal with what is cyber bullying and types of it. We also discuss about the cyber bullyin taking place at various places like school, college, university etc.Even we conducted a small survey ar unstructured interviews with the teachers, professionalisms about the cyber bullying. So in the results $n$ discuss about the survey and interview results after properly analyzing it. We also give some of the way th. how to stop cyber bullying and its limitations to fight with it easily

\section{Keywords: Bullying, Cyberbullying, Social media, Teachers etc.}

\section{Introduction:}

When we are talking about that today world is full of technology, and then we forgot sometimes that technology can be used in a negative way in an intention of harming others. So its negative can be called Cyber bullying. So cyber bullying done to harm others self- esteem and make him/her mentally depressed but generally girls are the most vulnerable victims of cyber bullying.

\section{1 literature review:}

The research paper on this topic is very less but study of various papers suggests that how cyber bullying affects especially teenagers that how they are undergoing with cyberbullying and also suggest the some of the ways to tackle with the cyberbullying. Some of the papers also suggest about that how the counseling plays a very important role in providing the relief therapy to the victims of cyberbullying.But especially teachers and parents role comes into play to observe the Students carefully and guide them properly.

\section{Definition Of Cyber bullying:}

Cyber bullying means when we are harming or hurting others by the use of technology. It can be on various platforms like E- Mail. Facebook, Instagram, etc.

\subsection{Types of bullying:}

1. Offline Bullying

When we are talking about the offline bullying it also associated with the term Ragging because when someone hurt you by saying some inappropriate words and harass you. Like mostly seniors bullied the juniors students just to show them very cool.

\section{Online bullying:}

It is a bulling related with the social media platforms, e- mail and much more. In an online bullying the person who is bullied, and the other person who are attempting bullying both are invisible. On a virtual platforms this bullying are happening. So the person makes a fake profile to 
www.rspsciencehub.com

hurt someone self esteem. Mostly girls facing a lot of online bullying from the boys who show them love and make them trust on them and then they blackmail the girls about their privacy content. For example: This is real story associated with the online bullying shared by the one of the teacher during the interview that there is a Girl, who is bullied by the gang of boys. One day that girl is scrolling a face book and send received a friend request in facebook by a boy and the she accepts it. After one day pass they share on their numbers, talking to each other and girl trust that boy a lot but she didn't knew that what bad happens to her. After some days pass boy invite a girl to his house and they share some private moments, after that boy starts blackmailing the girl so she is in fear a lot that after someday of this incident she committed suicide. So not about this story many people facing a cyberbullying on different platforms and by the different ways.

2.2 Ways to done cyberbullying:

1. By using inappropriate words

2. By sending inappropriate words

3. By physical and verbal abuse

4. By blackmailing someone

2.3 Platforms where cyberbullying takes place:

1. FACEBOOK

2. INSTAGRAM

3. TWITTER

4. WHATS APP

5. G-MAIL

6. SNAPCHAT AND MANY MORE.

\section{Status Of Cyberbullying Especially In India:}

In India cyberbullying status is not very good. Mostly $75 \%$ of the cases were reported in last two years against cyberbullying. Some of the cases are unsolved and mostly cases were not reported. The person who is bullied sometimes undergoing depression, trauma and were sometimes leads to suicides. In India sometimes the narrow mindset they never reported a cases especially if a girl harassed by a boy online. According to the survey conducted in 2012 they were reported that there is increased in 25 percent cases of bullying in India.

\subsection{Facts of cyberbullying in indian aspect:}

In Indian aspect the cyberbullying is a biggest issue because here people take revenge using online platforms a lot. In Indian society law
Volume 02 Issue 07 July 2020

were treated as a game, the rich people or powerful people break it very easily. Only rural areas people suffered a lot. But middle class person if they undergoing with a cyberbullying they never raise a voice because of financial or status strata. Mostly families also teaches a girl to be silent if something bad happens to you that's why in India the cases in comparison to other countries are more as in other countries they do not have a orthodox mindset.

\subsection{Cyberbullying at various places:}

Students are facing cyberbullying at school, college because of some personal conflict between the friends. At work places, the person are bullied by different ways in which people faces an abusive mistreating happening with them. The strata of cyber crimes increases day to day life.

\section{Method of study:}

As a methodology we take unstructured interview of different people working as a teacher, manager and even of student also. After that we have conducted online survey on cyberbullying. After properly analyzing the question we discuss the results.

\subsection{Findings Of The Study:}

We find that the $50 \%$ of the person suffered or suffering from cyberbullying and they face it mostly at school level. Mostly $68 \%$ person thinks that girls are the most vulnerable group that is mostly harassed by the means of online platforms. But when it comes to the symptoms or the solution that how we tackle cyberbullying mostly person are not aware of it

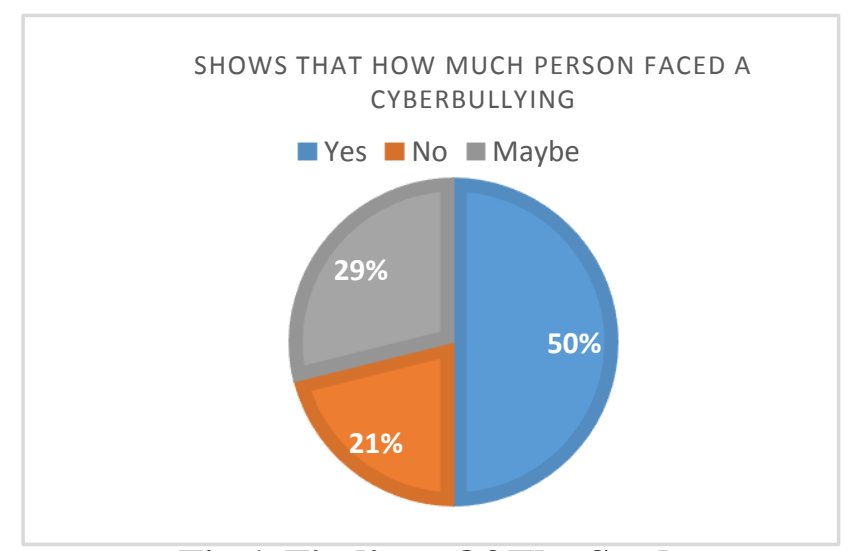

Fig.1. Findings Of The Study 
PERCENTAGE OF PEOPLE WHO THINK GIRLS

MOSTLY FACE CYBERBULLYING

a Yes no

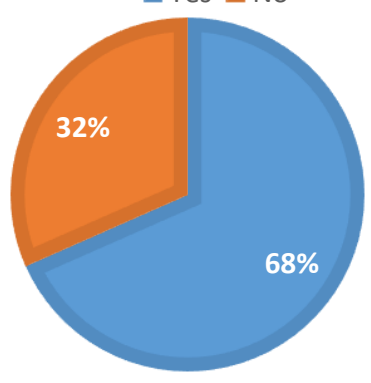

Fig.2. Percentage of people who think girls mostly face cyberbullying

\section{Symptoms Of Cyberbullying:}

Mostly it is tough to identify that person is facing a cyberbullying so here some of the ways we can identify:

1. Anxiety

2. Depression

3. Loss of appetite

4. Frustration

5. Try to do suicidal attempts

6. Communication pause

\subsection{How To Stop Cyberbullying:}

1. Proper guidance:

If a person undergoing cyberbullying proper guided he can overcome or fight with the situation boldly.

2. Take a help of adult:

If you feel that you are bullied take a support from others.

3. Counselling:

Take a proper counseling from psychologists if you have symptoms related to mental illness.

4. Report The Issue

Report the issue instead of sitting quietly.

5.Take proper time:

Take proper time to trust to someone whom you met online and think twice before sharing any personal details to anyone.

\section{Conclusions:}

Cyberbullying is a biggest issue so the concern authorities should take a proper action to control it. In a school we should have a proper counselling room to provide a comfort to the students. At the work level we can try to be conserving ourselves to share our personal details. It is easy to say that we can block the persons who are fake but this is the only key step to tackle cyberbullying fully.

\section{References}

\section{Journals}

[1] Peter P. KIRIAKIDIS DeMarques LAKES, A Case Study of Student-to-student Cyber Bullying in one High School, ISSN: 20667329(print),ISSN: 2067-9270

[2] Qing Li, (2010), Cyberbullying in High Schools: A Study of Students' Behaviors and Beliefs about This New Phenomenon, ISSN: 1092-6771

[3] Sherri Gordon,(2002), 6 types of Cyberbullying 